\title{
Prejudice in Testimonial Justification: A Hinge Account
}

\author{
Anna Boncompagni \\ University of California, Irvine, California, USA \\ Email: anna.boncompagni@uci.edu
}

(Received 25 August 2020; revised 5 June 2021; accepted 6 August 2021)

\begin{abstract}
Although research on epistemic injustice has focused on the effects of prejudice in epistemic exchanges, the account of prejudice that emerges in Fricker's (2007) view is not completely clear. In particular, I claim that the epistemic role of prejudice in the structure of testimonial justification is still in need of a satisfactory explanation. What special epistemic power does prejudice exercise that prevents the speaker's words from constituting evidence for the hearer's belief? By clarifying this point, it will be possible to address two more general issues concerning the nature of prejudice: its resistance to counterevidence and the steps involved in overcoming prejudice. I propose a hinge account of prejudice, based on the recent perspective of hinge epistemology, to help clarify these aspects. According to the hinge account, prejudices share a fundamental feature with hinges: they work as norms of evidential significance, and as such, they determine what can and cannot count as evidence for belief.
\end{abstract}

Keywords: Prejudice; testimony; testimonial injustice; testimonial justification; trust; hinges; hinge epistemology; Wittgenstein; Miranda Fricker

\section{Introduction}

Since the publication of Miranda Fricker's seminal Epistemic Injustice (2007), a whole field of study has flourished that focuses on how prejudice impacts credibility judgments in epistemic exchanges and harms human beings in their capacity to know and contribute to knowledge.

One aspect that this literature highlights is that in the presence of a prejudice, the relationship between evidence, belief, and justification is peculiar. In the case of testimony, in particular, when a prejudice is in place against a marginalized social group, a person belonging to that group is typically considered not credible, or not as credible as she should be. The reason is that the testimony of a person who belongs to a marginalized group is not taken as evidence for the corresponding belief on the part of the hearer. While in ordinary circumstances (and absent defeaters) a hearer takes it for granted that the speaker is a reliable informant and, hence, the speaker's words constitute a form of evidence, if a prejudice is in place, the reliability of the speaker does not go without saying. Quite oppositely, it is questioned, and their words openly 
disregarded. The naturalness of testimonial knowledge - the way a hearer ordinarily believes a speaker without much thinking - is blocked.

Though research concerning epistemic injustice has focused on the effects of prejudice, I argue that the account of prejudice that emerges in Fricker's view is not completely clear. More specifically, I claim that the role of prejudice in the structure of testimonial justification is still in need of a satisfactory explanation. What role does prejudice play in the justificatory structure of our beliefs? In the eyes (or ears) of the prejudiced hearer, why do the speaker's words not count as evidence for belief? This is the main object of the paper. To clarify, even if I am asking about the hearer's perspective on their epistemic situation, I am concerned not with the psychology but with the epistemology of prejudice in testimony. I am not interested in the hearer's motivations and desires nor the workings of the hearer's mind but rather the structure of testimonial justification, that is, in how prejudice can appear to normatively legitimate downgrading testimony by altering (for the hearer) the relationship between evidence, justification and belief. I am not seeking a causal explanation of the mechanisms of prejudice but a conceptual clarification of its normative role in the structure of justification. $^{1}$

By examining this issue, it is also possible to shed light on two related and more general issues concerning the nature of prejudice. The first is its resistance to counterevidence. How is it that even when presented with proofs contrary to her conviction, the prejudiced person dismisses such proofs without (seemingly) the slightest need to examine and evaluate them? The second issue has to do with the overcoming of prejudice and hence with epistemic justice. What exactly changes in the epistemic status of a prejudice once it is seen by those who hold it as a prejudice and not merely as a sort of empirical generalization? There is indeed a difference between the realization that one takes certain presuppositions for granted and the realization that these presuppositions are prejudices. Although the importance of these two related issues extends beyond Fricker's account of testimony, I focus on Fricker, as her framework nicely shows what is at stake and allows me to streamline the scope of this paper.

My theoretical ally in this project is the recent perspective of hinge epistemology, a development of Wittgenstein's reflection concerning the 'hinges' on which our epistemic practices turn. I propose a hinge account of prejudice and argue that this account clarifies the following three aspects described above: the role of prejudice in the structure of testimonial justification, the resistance of prejudice to counterevidence, and the different steps involved in overcoming prejudice. To anticipate, my central claim is that prejudices share a fundamental feature with hinges: they work as norms of evidential significance, and as such, they determine what can and what cannot count as evidence.

In the following, I first address how Fricker's work deals with prejudice and highlight what I consider to be still lacking in her perspective. Then, I introduce hinge epistemology and propose a hinge account of prejudices, thus explaining why this account helps overcome the difficulties in Fricker's view. Finally, I consider some objections and conclude.

\section{Prejudice in testimonial justification}

In its most general terms, epistemic injustice consists of the injustice of being diminished as epistemic agents or knowers. In the example that Fricker (2007) offers at the beginning of her book, this is the harm suffered by Marge in Anthony Minghella's screenplay of The Talented Mr. Ripley when she is addressed by Mr. Greenleaf with

\footnotetext{
${ }^{1}$ I thank an anonymous reviewer for helping me clarify this point.
} 
the words 'Marge, there is female intuition, and then there are facts'. Because of her belonging to a social group, or in this case a gender, and because of prejudices connected with it (women are too emotional or irrational), Marge is discredited as a knower. $^{2}$

In the history of philosophy, some approaches, i.e., most notably Hans-Georg Gadamer's ${ }^{3}$ approach, address prejudice in ethically neutral terms by considering prejudice an inevitable element of judgment; however, researchers focusing on epistemic injustice following the common usage of the term and the literature related to psychology, sociology, and moral philosophy connect prejudice with the culpability of neglecting evidence and the influence of bad affective elements on the capacity of the subject's judgment (Fricker 2007: 35). In what follows, I will take Fricker's definition (below) as the starting point for my reasoning without disputing this negative connotation. A wider investigation into the notion of prejudice would be fascinating, but it lies outside the scope of this paper.

In Fricker's words (2007: 35), a negative identity-prejudicial stereotype, or identity prejudice, is defined as follows:

IP - A widely held disparaging association between a social group and one or more attributes, where this association embodies a generalization that displays some (typically, epistemically culpable) resistance to counterevidence owing to an ethically bad affective investment.

What distinguishes a prejudice from a stereotype, which in Fricker's view is a mere generalization concerning a social group, is that the subject holding it resists evidence against the prejudice, and such resistance is blameworthy. In epistemic testimonial exchanges involving a speaker belonging to a prejudiced group, identity prejudice will typically result in the attribution to the speaker, on the part of the hearer, of a lower degree of credibility than her due. This credibility deficit is the main harm of what Fricker calls 'testimonial injustice', one of the two types of epistemic injustice that she investigates, the other being 'hermeneutical injustice'. In this paper, I will deal with the former.

The attribution of a certain degree of credibility to a speaker is a process that normally does not require explicit inference or reasoning. Indeed, following the footsteps in the literature concerning moral perception, Fricker adopts a perceptual model of credibility judgment according to which in most everyday epistemic exchanges, the hearer does not deliberate regarding how much to trust the speaker but directly perceives the speaker as trustworthy to a certain degree (Fricker 2007: 71). In an Aristotelian fashion, Fricker also claims that sensibility in epistemic perception, as in moral perception, can be trained. In contrast to testimonial injustice, it is possible to cultivate the virtue of testimonial justice due to which we are able to reflect actively upon the background assumptions guiding our perception of others' trustworthiness and eventually neutralize the impact of prejudice in our credibility judgments (2007: sections 3.3 and 3.4).

Let me now focus on the structure of testimonial justification and how it is impacted by prejudice in Fricker's account. In normal circumstances, absent defeaters, testimony is believed. If I ask a passerby for directions, and I have no reason to doubt them, I

\footnotetext{
${ }^{2}$ As highlighted by McKinnon (2016: 438-9), although Fricker 'baptized' the concept, work concerning epistemic injustice, particularly in black feminist thought, already abounded before her book was published. See for instance, Moraga and Anzaldúa (1981), hooks (1992), Collins (2000) and Spivak (2003).

${ }^{3} \mathrm{His}$ battle against 'the Enlightenment prejudice against prejudice' is well known; see Gadamer (1975: 234-74; 1976: 3-17).
} 
simply believe their words. I take them as evidence for what they assert. Studies on the epistemology of testimony abound concerning what is at stake here. While it is commonly acknowledged that in ordinary circumstances, belief in testimony is justified by virtue of a general trust in the speaker, reductionists and antireductionists debate over whether independent reasons are needed for this basic commitment itself to be justified. Without lingering on the debate (see Lackey 2011 for an overview), suffice it to say that normally, absent defeaters, a basic trust in speakers' sincerity and knowledgeability provides testimonial justification. Call this, provisionally, 'basic trust presupposition' (I will expand on this soon). Consider now Fricker's example from The Talented Mr. Ripley. When Marge tells Mr. Greenleaf that his son might have been killed by Mr. Ripley, her testimony is not considered trustworthy due to the negative prejudice characterizing the female gender as too emotional or irrational and therefore unreliable. Mr. Greenleafs prejudice against women prevents him from considering Marge's words as evidentially significant for the (true) belief, P, 'My son was killed by Mr. Ripley'. Were his judgment not guided by prejudice, Mr. Greenleaf would consider this belief justified based on Marge's testimony and by virtue of the basic trust presupposition. Thus, my question is: what role does prejudice play in the justification of testimonial belief? In Fricker's definition of prejudice as well as her general treatment of the matter, the answer does not emerge clearly. At first sight, prejudice seems to erode the basic trust presupposition that otherwise would regulate Mr. Greenleaf s judgment. However, how can a prejudice, which seems to be something essentially cultural and local, impact a general basic principle such as trust? Fricker's account refers to moral and psychological aspects, such as the blameworthiness of this behavior, roughly as follows: prejudice ought not to interfere, but it does, and this happens because the prejudiced person is ethically bad and/or psychologically malfunctioning (or the collective hermeneutical resource is unjust and hosts prejudices). However, without downplaying the relevance of these factors, I think that more can be said upstream - before addressing the issue of blame - to clarify the structure of justification and the role that prejudice plays in it. Is prejudice comparable to a defeater that undermines a certain belief, such as belief in the speaker's words in this case? Alternatively, does prejudice prevent the hearer at the outset from counting such words as evidence for belief? My claim is that hinge epistemology helps elucidate this issue. I address this point in section 4 after presenting the hinge account of prejudice.

In addition, the hinge account is helpful in addressing two other issues concerning the nature of identity prejudice. Here, I confine the discussion to those identity prejudices that have a propositional form or that, once voiced, assume a propositional form of the type 'People like $\mathrm{x}$ are ...', independently of the psychological form they might take. ${ }^{4}$ One issue that the hinge account clarifies concerns resistance to counterevidence. Propositions of the kind "People like $\mathrm{x}$ are..." seem to express empirical beliefs. However, if prejudice is an empirical belief, then, like any other belief, it should be subject to the tribunal of experience. 'Women are unreliable', as an empirical belief, should be subject to revision once evidence proves that women are not unreliable (or at least once enough evidence proves it; cf. Begby 2013; Silva 2020). However, prejudice seems to be 'immune' to empirical counterevidence - in fact, one might say this is what makes it a prejudice. Fricker's notion of identity prejudice (IP) considers this resistance a defining feature of prejudice and claims that the reason is bad affective

\footnotetext{
${ }^{4}$ As Fricker $(2007: 15,37)$ suggests, these prejudices might in fact be characterized as implicit images rather than explicit beliefs; however, once they are made explicit, they generally do assume a propositional form.
} 
investment'. This again is a moral/psychological account. ${ }^{5}$ However, considering resistance to counterevidence chiefly from the point of view of moral and psychological factors risks hiding that more work is needed to reveal the normative conditions that enable belief justification and belief revision and how prejudice can alter such conditions. Without substituting an explanation based on moral and psychological factors, the hinge account clarifies how the epistemic structure of a prejudiced testimonial exchange differs from that of an unprejudiced testimonial exchange.

Finally, a related difficulty faced by research investigating epistemic injustice is that if IP remains implicit in our background assumptions, it becomes hard to determine precisely how the virtue of testimonial justice can work or even how it can develop (Alcoff 2010). Fricker herself acknowledges the difficulty of stepping outside one's own background when prejudice becomes part of a structural oppression and affirms that there are historical and cultural circumstances in which this virtue simply cannot be achieved (2007: 99). In such circumstances, testimonial injustice can be nonculpable (2007: 100) because the critical concepts necessary to correct prejudice are not available to the subject. What is called for in these cases, Fricker argues, is an exceptional (as opposed to a routine) move in a moral discourse. When the exceptional alternative is, 'as a matter of historical possibility, just around the corner' (2007: 105), Fricker adds, a person can be held responsible for adopting it or not. Arguably, the following question arises: how does the virtue of testimonial justice develop in this intermediate situation when the moral predicament is changing and a person is not culpable and yet is responsible for her judgment being prejudiced? Apart from the difficulties involved in these distinctions at the ethical level, Fricker's analysis seems to leave the epistemic aspect hidden from view. There is indeed a moment when one realizes that what one thought a mere generalization was actually a prejudice; in that very moment, the correct relationship among testimony, evidence, and justification is restored. I am interested in clarifying what precisely changes in this passage. An important aspect to consider is that to neutralize the effect of prejudice, hearers must be able not only to see the presupposition that is operating in their reasoning but also to see it as a prejudice. Two steps seem to be involved here.

In summary, I argue that more than description based on psychological, social, or moral factors can be given concerning the specific role played by prejudice in testimonial justification. In addition, and relatedly, further clarification is possible concerning two more general aspects of prejudice: resistance to counterevidence and the overcoming of prejudice. In section 3, I will introduce hinge epistemology and propose a hinge account of prejudice. Next, after connecting the topic to other epistemological notions (undercutting defeaters, higher-order evidence, and epistemic preemption), I argue that the hinge account is a powerful tool for a better understanding of the three aspects highlighted above.

\section{A proposal: the hinge account}

The perspective of hinge epistemology is a development of Ludwig Wittgenstein's metaphor of hinges from his later notes published as On Certainty. These remarks illustrate that our ordinary epistemic practices are anchored in unquestioned background assumptions, such as 'I am a human being', 'The external world exists', 'There are physical objects', or 'The earth has existed for a very long time' (Wittgenstein 1969, hereafter OC, \#4, 20, 36, 233). Wittgenstein observes: '[T]he questions that we raise and our

\footnotetext{
${ }^{5}$ This is indeed the default account in virtue (and vice) epistemology; see Zagzebski (1996) and Cassam (2016).
} 
doubts depend on the fact that some propositions are exempt from doubt, are as it were like hinges on which those turn' (OC \#341). Hinges usually remain unnoticed, implicit and unspoken, as they are obvious presuppositions of knowledge practices that in ordinary circumstances simply go without saying.

Wittgenstein was not the first philosopher to point out that there is a set of background assumptions, presuppositions, commitments, or basic beliefs that have this peculiar status. Thinkers such as Thomas Reid, John Henry Newman, Charles S. Peirce, R.G. Collingwood, and G.E. Moore, highlighted the centrality of these presuppositions in human epistemic practices. ${ }^{6}$ However, one aspect of Wittgenstein's distinctive contribution to this topic concerns the clarification of the relationship between this special class of assumptions and ordinary empirical propositions. While grounding everyday empirical propositions, hinges indeed remain ungrounded and ultimately unjustifiable. To show this with an example, take the proposition "the Earth has existed for a very long time". One might say that this is an empirical proposition supported by evidence, such as that radiometric dating proves that the Earth is 4.5 billion years old; we use carbon 14 to determine the age of organic remains; and stratigraphy and fossils explain the age of geological layers. In short, a multiplicity of scientific data indicates that the Earth has existed for a very long time. Now, take a king who believes that the Earth was created when he was born as an example. He was raised with this conviction, and everyone around him constantly confirms it. For him, would carbon 14 dating constitute evidence that the Earth existed for a long time before his birth? Certainly not. Most likely, he would claim that carbon 14 itself, fossils, historical documents, etc. were all created when the Earth was created - namely, when he was born (cf. OC \# 190; Coliva 2015: 1). In other words, only if we take for granted that the Earth has existed for a very long time can carbon 14 constitute evidence of the age of a geological layer. "The Earth has existed for a very long time" is a hinge or a presupposition that is part of our worldview. No empirical observation can truly prove or ground our presupposition or our hinge because any empirical observation relies on such implicit presupposition or hinge. Given the hinge, we can use carbon 14 and fossils to date a geological layer, and we can use them as evidence for the belief that "this geological layer is $x$ years old". Our belief is justified by virtue of the evidence and the hinge grounding such evidence. Therefore, hinges play a normative role with respect to evidence: hinges are the basic rules of evidence that allow ordinary empirical propositions to be justified.

However, this does not mean either that hinges express necessary truths or that the role of a hinge is fixed once and for all. There is indeed room for variability here. Depending on the context, a proposition can play the role of a hinge or the role of an ordinary empirical proposition. For example, 'I have two hands' in ordinary circumstances is a hinge, but if uttered after a surgical operation, it is subject to doubt and verification.

'Hinge epistemology' is a growing field of studies that takes its cue from these reflections. Its principal aim, to date, has been the development of an antiskeptical strategy based on the acknowledgment of the unwarrantability of hinges (Coliva 2015; Coliva and Moyal-Sharrock 2016; Pritchard 2016; Schönbaumsfeld 2016). However, the significance of the Wittgensteinian intuition goes much beyond this and proves particularly helpful in social epistemology, as more recent research has shown (Ashton 2019; Boncompagni 2019; Coliva 2019a, Forthcoming; see also Greco 2016; O’Hara 2018; Ranalli 2018; Coliva and Palmira 2020, Forthcoming).

\footnotetext{
${ }^{6}$ See Reid (1997 [1764], 2002 [1785]), Newman (1979), Peirce (1935 [1905a], 1935 [1905b]), Moore $(1925,1939)$, and Collingwood (1940).
} 
Note that, unlike ordinary knowledge claims, hinges are not subject to proof or justification and remain essentially invulnerable to empirical evidence. I observed above that the same holds for prejudice. This parallelism suggests that it is possible to use hinge epistemology as a means for understanding how prejudice works.

It might be objected that such a move is not tenable because hinges appear to be much more basic than prejudices and are not subject to cultural variability - think of 'There is an external world' (Coliva 2015: 34) or 'I am not radically and fundamentally mistaken in my beliefs' (Pritchard 2016: 95). However, the applicability of hinge epistemology in the social domain clearly emerges when one considers that some of Wittgenstein's examples of hinges are essentially local, to use Moyal-Sharrock's terminology and classification (2004: Ch. 7). That the Earth is round (OC \#291), that it is not possible to go to the moon (OC\#286), or that a king can make rain (OC \#132) are or were all examples of local or culture-specific hinges. In fact, the second and third examples are cases of past local hinges, or of hinges of different societies, that are not universally held. Since they can vary across time and space, local hinges are, to a certain extent, 'give-uppable' (Moyal-Sharrock 2004: 136-47; see also Pritchard 2016: 95-6). However, because of their implicitness and their 'going without saying', it is not easy to recognize their presence, let alone their dubitability.

The notion of hinges, I submit, is particularly helpful for the analysis of the role of prejudice in the epistemology of testimony.

Recall Fricker's definition of identity prejudice (IP):

IP - A widely held disparaging association between a social group and one or more attributes, where this association embodies a generalization that displays some (typically, epistemically culpable) resistance to counterevidence owing to an ethically bad affective investment.

Leaving aside for the moment, for the sake of simplicity, the ethically negative elements in the definition (disparagement, culpability and bad affective investment), we might say that the epistemic core of the definition is as follows:

[IPcore] - An association between a social group and some attributes, where such association embodies a generalization that is typically resistant to counterevidence.

This definition can now be compared with the notion of a hinge, which I propose to define as follows:

$\mathrm{H}$ - An unjustified and unjustifiable taken-for-granted presupposition that regulates judgments and/or behavior in a given domain.

I prefer the expression 'taken-for-granted presupposition' to 'assumption' (Coliva 2015) or 'commitment' (Pritchard 2016) because the latter words might be interpreted as suggesting that there is some active and voluntary element in assuming or committing oneself to a certain hinge. 'Taken-for-granted presupposition' instead is meant to underline the passivity of inheriting hinges without reflection. Something that we 'take' (for granted) is definitely not something that we intentionally make, and a 'presupposition' is already there, 'pre'-supposed in our epistemic practices. ${ }^{7}$ The unjustifiability of hinges derives precisely from this "pre" feature, which is, as I am going to explain shortly, a

\footnotetext{
${ }^{7}$ This is merely a terminological choice: I am not referring to presuppositions as studied in the philosophy of language, linguistics, or discourse analysis, though it would probably be interesting to develop such
} 
normative "pre". Hinges are unjustifiable not in virtue of their content but in virtue of their normative epistemic role.

The definition that I give is admittedly broad, as is the array of examples that Wittgenstein offers in OC, which range from "There is an external world" to "Cats do not grow on trees" and from "Every human being has two human parents" to "Objects do not disappear when you put them in a drawer" (OC \#\#20, 282, 239, 134). There is a debate among commentators regarding whether all these examples should be considered hinges, given the role that they play in our practices, or whether we should define this notion in stricter terms (Moyal-Sharrock 2004 and Coliva 2015 can be considered examples of the former and latter views, respectively). I am not interested in taking a position here as I do not think that it is essential for the argument; what is essential is that certain presuppositions in certain contexts play a normative role with respect to our actions and judgments.

In regard to identity prejudices (IPs) in testimonial exchanges, the point is that there are presuppositions that impact credibility judgments, and therefore, this is the aspect of hinges that is relevant to our purposes and that I am going to use. ${ }^{8}$ If we now combine the epistemic core of identity prejudices (IPcore) with the notion of hinges $(\mathrm{H})$, interpreting IPcore as a kind of $\mathrm{H}$, we find that the epistemic core of an identity prejudice that embeds the notion of hinges (HIPcore) is as follows:

HIPcore - An unjustified and unjustifiable taken-for-granted presupposition associating a social group and some attributes, where such association embodies a generalization that is resistant to counterevidence and regulates judgments in a given domain.

Adding the negative elements that we provisionally set aside and eliminating some redundancy, we obtain what I call the hinge account of identity prejudice (HAIP):

HAIP - A hinge that associates a social group and certain disparaging attributes, regulates judgment towards that social group, and displays some (typically epistemically culpable) resistance to counterevidence owing to an ethically bad affective investment.

This account leaves the moral elements of Fricker's definition untouched; it is not my aim to focus on these issues. The most significant addition that the hinge component makes to Fricker's definition is the normative element according to which prejudices regulate judgment. ${ }^{9}$

In the case of testimony, the hinge account predicts that exactly like hinges, prejudices contribute to the framework within which credibility assessments take place. Similar to hinges, prejudices are (or at least can be) norms of evidential significance (Coliva 2015, 41) determining what does and what does not count as evidence for belief.

an explicit connection. Notice that Collingwood uses 'presuppositions' in what has been named his version of hinge epistemology (Collingwood 1940; D’Oro 2018).

${ }^{8} \mathrm{I}$ am not claiming that identity prejudices do not impact our behavior; they obviously do. However, I am here interested in investigating their effect on judgment.

${ }^{9}$ Notably, this account does not rule out the possibility that hinge-prejudices are context-sensitive and triggered by contextual cues, which is an aspect highlighted in the literature concerning the psychology of prejudice (see for instance Wittenbrink et al. 2001; Castelli and Tomelleri 2008; I thank an anonymous reviewer for bringing this to my attention). Although hinge-prejudices play a normative role with respect to evidence, they often do so contextually and in connection with a net of other culture-specific hinges that may be present or absent in any given context. I further discuss the "locality" of hinges in section 5. 
Hinge identity prejudices, in other words, decide whether what a person says has evidential significance. This is what is at stake in testimonial justification.

\section{The hinge account, unpacked}

Let us now observe the advantages of the hinge account by considering the issues pointed out in section 2 .

The first element is the role of prejudice in the structure of testimonial justification. Coliva (2019a, Forthcoming) proposes an extension of hinge epistemology to testimony. For someone to be justified in believing what another person says on the basis of this person telling her, Coliva claims that a hinge must be in place concerning the reliability of the speaker. Indeed, the belief originating in testimony (i.e., belief in what one is told) is justified only if the hearer takes it for granted that the speaker is trustworthy, i.e., sincere and knowledgeable with respect to P. In ordinary circumstances, this hinge, which I earlier called 'basic trust presupposition' and, following Coliva, we can now call 'testimonial hinge', just goes without saying, as an attitude of trust generally characterizes unproblematic testimonial exchanges. However, what happens when instead of the default testimonial hinge, a hinge-prejudice is in place by virtue of which the speaker is automatically deemed not trustworthy by the hearer (i.e., insincere and/or not knowledgeable with respect to $\mathrm{P}$ )? In this case, as Coliva briefly considers at the end of her paper, testimonial justification becomes 'rationally (or cognitively) unavailable' (2019a: 64) to the hearer. The hearer would be justified in believing what they are told, but the presence of the hinge-prejudice prevents them from having such justification available, which is enough for them to discount the testimony. Hence, prejudice disrupts the testimonial hinge that usually regulates credibility judgments.

How should we characterize such disruption?

One way of thinking of it is as an undercutting defeater, in that prejudice rescinds the evidential relationship between testimony that $\mathrm{P}$ and $\mathrm{P}$, or as higher-order evidence, in that it puts in doubt or brackets what justifies this relationship, that is, the hearer's ordinary confidence in the speaker's testimony. ${ }^{10}$ However, it is unclear whether a presupposition that lacks justification, such as a hinge-prejudice, can constitute a defeater or higher-order evidence. Moreover - and this is what I would like to focus on - these characterizations are probably not the best candidates for portraying a key feature of prejudices or presuppositions: the 'pre-' in them. A prejudice or a presupposition seems to intervene before a justification is established, which allows testimony that $\mathrm{P}$ to work as evidence for $\mathrm{P}$; prejudice seems to prevent it rather than removing it once established. In hinge terminology, the hinge-prejudice here is preventing the testimonial hinge from playing its role by taking its place; in this way, it prevents the speaker's words from being considered evidence. It does so locally because it is attached to a social group and to a specific sociocultural-historical context. ${ }^{11}$ What this suggests is that the testimonial hinge is actually neither global nor individual but tailored to social identities. To put it differently, what justifies testimony is neither 'People are trustworthy' nor ' $\mathrm{T}$ is trustworthy' ${ }^{\text {'2 }}$ but 'People like $\mathrm{T}$ are trustworthy'; sometimes, the

\footnotetext{
${ }^{10}$ The difference between undercutting defeaters and higher-order evidence is a subject of debate (Feldman 2005; Christensen 2010), and of course much derives from how these notions are defined. I am following Christensen (2010) here; however, the point I am making does not depend on this difference.

${ }^{11}$ It might be objected that a local hinge cannot override a general hinge. I consider this objection in the next section.

${ }^{12}$ I am referring here to the two characterizations of testimonial hinges offered by Coliva (2019): the global one, 'People are generally reliable informants', and the local one, ' $\mathrm{T}$ is a reliable informant on this occasion'.
} 
hinge-prejudice 'People like T are not trustworthy' stands in the way, preventing testimonial belief from being justified. Therefore, although a hinge-prejudice works similarly to an undercutting defeater (or provides higher-order evidence) on testimonial justification, in contrast to other defeaters that typically lead to belief revision (or higher-order doubt), it somewhat inhibits justification in advance by working in the place of the testimonial hinge.

The term preemption captures what I am gesturing at. Keren (2007) and Zagzabski (2012) talk of preemption as the mark of epistemic authority: we take the beliefs of those whom we recognize as our epistemic authorities on a certain matter as preemptive with respect to our own reasons on that matter. This notion has been a subject of debate and criticism (Keren 2014a; Jäger 2016; Dormandy 2018), not least because it seems better suited to describing an epistemic vice than a virtue (Wright 2016). I agree with the criticism, and indeed, in my view, preempting is what prejudices typically do: they preempt evidence against them. ${ }^{13}$ In cases of testimonial injustice, a prejudice preempts evidence by means of 'source discrediting' (Begby 2020) and, more specifically, by undermining the hinge that in an unprejudiced environment would guarantee testimonial justification. The evidence that a person's testimony offers is not taken as evidence, and the belief does not appear justified because the basic commitment to the speaker's trustworthiness (the testimonial hinge) is not working. A hinge-prejudice that discredits the speaker is working in its place. Note that the effect of preemption is, in the end, the same as that of certain kinds of defeaters (cf. Constantine and Grundmann 2018), but the terminology of preemption, I contend, allows us to better see the precedence of prejudice with respect to our ordinary epistemic practices. ${ }^{14}$ While a belief can be defeated ex post if the subject becomes aware of certain circumstances (e.g., the lighting was somewhat abnormal), preemption by source discrediting excludes ex ante information derived from a certain source. Prejudice works as a sort of evidential gatekeeper by not allowing information from a given source to count as evidence, that is, discrediting such information before it can be considered as evidence.

Begby's description of preemption in prejudices can easily be 'imported' into the hinge account. Building on his previous work (2013), Begby claims that the most serious problem with prejudices is their insidiousness, that is, the fact that because they are absorbed in childhood and early adolescence, they become entrenched or 'lodged in the mind' (2020: 9) and come to shape people's cognitive outlooks. The hinge account, in addition to this description, clarifies that the reason why hinge-prejudices preempt evidence is the normative role that they play in ordinary epistemic practices (cf. Zagzebski 2012). It is not merely because they are beliefs acquired in childhood, not merely because they 'come first', so to speak, that prejudices have this power on future evidence or counterevidence; rather, it is because they are hinges, and as such, they determine the rules of evidential significance. Not only their 'age' but also their epistemic role is different. The 'pre-' signals a normative precedence, not merely a chronological one, and preemption is a normative and not a merely chronological preemption. This explains prejudices' controlling power on taking others' testimony as evidence for one's beliefs. To reiterate and conclude on this point, when a hinge-prejudice is in place against a speaker, it normatively precludes the hearer from considering the speaker's words as evidence and the corresponding belief as justified. It does so by substituting the

\footnotetext{
${ }^{13}$ Fricker talked of 'preemptive testimonial injustice' when dealing with one of the forms that silencing assumes: there is preemptive testimonial injustice when a person belonging to a marginalized social group is not asked to provide information (as opposed to not being believed when she does; 2007: 130-1). I am using the notion of preemption in a broader sense.

${ }^{14}$ See also Keren $(2014 b)$, who offers a 'preemptive reason account' of trust.
} 
ordinary testimonial hinge that would otherwise regulate credibility assessment and justification.

So much for the role of prejudice in testimonial justification.

I would now like to use hinge epistemology to address two more general aspects of Fricker's notion of prejudice. The first is the explanation of the epistemic mechanisms involved in resistance to counterevidence. Note that we are concerned here not with the words of the speaker being taken (or not taken) as evidence for the corresponding belief but with prejudice itself being immune to counterevidence. This aspect of prejudices is indeed widely acknowledged and discussed in the literature, ${ }^{15}$ but it is usually the psychological mechanism and its moral blameworthiness that are highlighted. Thus, what emerges is that prejudice is essentially a wrong judgment and that we are prone to it because of how our minds work: our reasoning and our behavior are influenced by factors that are unrelated to how things are. There is something left unexplained here from the epistemological point of view. The causes of prejudice might be psychological or social, and prejudice might have important moral implications, but I believe that its functioning in the normative structure of justification requires a better description. Hinge epistemology provides one: counterevidence is not effective because it is simply not perceived as evidence due to the normative force of the hinge-prejudice. More than an empirical disconfirmation is needed for the hinge to be neutralized. To illustrate this notion with an example, if it is a part of one's system of hinges that a king can make rain, the fact that on a certain occasion he did not would not be taken to disprove that hinge but would be accommodated through other assumptions and belief adjustments (cf. OC \#132).

Relatedly, the comparison with hinges also helps us see with more clarity the implicitness that often characterizes prejudices. Indeed, one might say that the less a prejudice needs to be explicitly asserted, the more it exercises its effects (as the vast amount of literature on implicit bias confirms). Hinges function in the same manner: it is by remaining unseen in the background that they perform their role, while uttering them might result in an admission of dubitability, hindering the automaticity that normally characterizes them (Boncompagni 2014). Interpreting prejudices as hinges is therefore also clarifying because it helps us conceptually grasp their implicitness, the silence or invisibility surrounding them, as aspects connected with their normative role.

According to Alcoff (2010), the implicitness of prejudices is not taken into due consideration by Fricker when she deals with the virtue of testimonial justice; it seems impossible, indeed, to correct involuntary implicit biases through voluntary and explicit acts, as possession of this virtue seems to require. If prejudices remain implicit, then even recognizing their presence, let alone correcting them, appears to be out of reach. This is a further difficulty in Fricker's account of prejudice, the last aspect I would like to focus on.

A hinge account allows us to see that there are actually multiple levels of difficulty that need to be distinguished. On the one hand, it might be difficult to see the taken-for-granted presuppositions that guide behavior and judgments; on the other hand, and in addition, it might be difficult to see that these presuppositions are prejudices. These two processes sometimes overlap because in the moment that a prejudice comes to the fore, it also emerges that it is indeed unjustifiably and unjustly exercising

\footnotetext{
${ }^{15}$ Begby (2013) is an exception. In his view, rather than resisting counterevidence, prejudices usually accommodate it because they have the form of generics. Unlike universal generalizations, which ascribe a particular property to each member of a group, generics have to do with what is typical for members of that group; therefore, they automatically make room for negative instances - in fact, they even predict them. See Silva (2020) for a response.
} 
normative power. However, it is important to distinguish these aspects because simply seeing a presupposition does not automatically entail seeing that it is unjust.

At the first level, it is the mere presence of the hinge-prejudice that emerges: we realize that there are some presuppositions that just stand fast for us, even if we did not explicitly learn them (cf. OC \#152). What are the conditions that allow us to see hinges? Self-reflection, arguably, can make us aware of them, but self-reflection itself is hardly something a person decides to do out of the blue without a motivation or a reason. If absolutely nothing comes in the way of a person's or a group's hinges, then it is very likely that these hinges will remain silent and implicit. Nothing calls for them to be perceived by those who hold them. What might happen, instead, is that other people or communities, who do not share those presuppositions, do see them from the outside, as it were. When outsiders point out our taken-for-granted presuppositions, we might finally be struck by them (Wittgenstein 2009: \#129; Medina 2013: 18-19). In this first phase, however, the epistemic status of a hinge is still normative, as it still regulates our judgment and behavior. In fact, we might even want to defend our hingeprejudice from external attacks or to teach it to children or newcomers. When we do so, we manifest to others that 'this is the way we act' and that this proposition, though empirical in shape, has a normative role (in saying 'this is the way we act', we are saying something like 'this is the way we act, and this is the way one obviously ought to act'). In this context, the alleged naturalness of hinge-prejudices must be positively asserted. Consider how often appeals to common sense come about precisely in defense of prejudices. When prejudices such as 'nonwhite people are cognitively inferior to whites', 'women are emotional, men are rational', or 'homosexuality is an illness' are asserted, indeed, it is also often insisted that it is obviously so, that there is no need to argue, and that everyone agrees.

The emergence of the presupposition as such is not necessarily problematic for those who hold a prejudice. Take the example of white supremacists: their convictions about the inferiority of nonwhite people are often in plain view, sometimes flaunted. However, what might happen next, and this marks the second level of the emergence of hinges, is that the hinge becomes questionable and finally is questioned. Radical doubts of it become conceivable, and radical doubters start to be listened to (Boncompagni 2019). This makes the hinge vulnerable: the reasons behind it might finally be examined.

Talk of reasons in a strict sense, to be sure, is not always appropriate. Sometimes, when there is a clash between worldviews embodied in different local hinges, people belonging to different forms of life are not able or willing to find a rational way to dialogue and defend their reasons. The issue of prejudice intersects here with the issue of deep disagreement, another topic to which hinge epistemology is contributing significantly (OC \#608-12; Fogelin 2005 [1985]; Pritchard 2018; Ranalli 2018; Coliva and Palmira 2020, Forthcoming; cf. Kappel 2018; Lagewaard 2020). Even when rational argumentation is not available, however, the presence of other systems of hinges can have the effect of putting our own hinges into doubt. This is the result of what Medina (2013) calls epistemic friction: for commonsense presuppositions to stop operating smoothly, some epistemic obstacle must block their path. This friction produces self-criticism, forcing one to compare and contrast one's own beliefs, to meet justificatory demands and recognize cognitive gaps (Medina 2013: 50, 176, 204; cf. Code 2008, 46-7). Within the terminology of hinge epistemology, what happens is that by being questioned, the hinge is brought back from a normative to an empirical role, back into the arena of what is disputable and needs justification. This second level is the crucial one for the overcoming of prejudice: it is in this moment that we see that the hinge of our judgments and practices is (was) indeed a prejudice in that it exercises (exercised) 
a normative power that has (had) no good reason to exist. Going back to cases of testimonial injustice, the model better explains the epistemic mechanism underlying the development of testimonial justice. At the normative level, hinge-prejudice stops exercising its preemptive control. Prejudice is no longer working in the place of the basic trust that normally rules testimonial exchanges. The content of testimony, by virtue of the testimonial hinge, now counts as evidentially significant for the justification of belief, and the hinge-prejudice is uncovered as merely an empirical proposition among others, subject to doubt and the tribunal of experience.

Note that these two aspects of the notion of prejudice that the hinge account helps clarify - its resistance to counterevidence connected to its implicitness and the steps involved in overcoming prejudice - are not limited to the case of testimonial justification, although the account that I proposed was targeted toward testimonial justification. However, I believe that its validity does extend beyond this specific case. One way of making such an extension of scope more explicit is by considering not only prejudice's role in regulating judgment but also its role in regulating, more generally, attitudes and behavior, which are broadly understood to include, for instance, unexpressed mental states, emotions, immediate reactions, etc. Recall that this is an aspect that I left out of my account precisely because I was limiting it to credibility judgments in testimonial justification (see section 3 and footnote 8). Although more work might be needed to flesh out in detail how a hinge-prejudice impacts attitudes and behavior, I see no obstacles in principle here. In contrast, this seem to be consistent with both a richer view of the role of prejudice in our life and a Wittgensteinian understanding of hinges as broadly shaping our actions, practices, and ways of seeing things.

\section{Objections}

Before concluding, I would like to consider three objections that might be raised against the hinge account. I will start from the last point I made and return upstream to the premises of the paper.

One might object that the hinge account does not actually explain the overcoming of prejudices. It does not offer solutions or even cues for addressing the real problem and hence does not go beyond what Fricker has already told us. Clarifying the normative relations among prejudice, evidence and testimony does not add anything relevant to our understanding of what needs to be done. Is such a problem not just left untouched by the hinge account? My reply is yes and no. Yes, it is left untouched in the sense that in this paper, I do not directly engage with what needs to be done to overcome prejudices. My account is aimed not at explaining how overcoming prejudices is possible (psychological, social, and political factors need to be taken into consideration for this) but at clarifying what changes occur in the normative structure of belief justification when such overcoming takes place. At the same time, no, the problem is not left completely untouched because the clarification that a hinge account offers has important consequences for understanding how prejudice works, more specifically at what level it works, and therefore also at what level something needs to be done. If prejudice has normative power over evidence, clearly, providing evidence to overcome it will not suffice. When data are shown to prejudiced people in the hope that they will revise their beliefs, such data will simply not be considered, i.e., the data will be either accommodated or ignored. Overcoming prejudices requires working at the level of hinges. A clearer understanding of the epistemic structure involved, I believe, contributes to focusing on the target that needs to be addressed as well as on the methods for addressing it. Since the target is a hinge, rational argumentation as a method might be unavailable, and persuasive practices might instead be most effective. Note that persuasion is 
not always irrational: persuasive techniques include making examples, using images, and suggesting comparisons, with the aim of allowing the interlocutor to see things from a different angle. The key here, indeed, is difference: to become aware of their prejudices, individuals and communities need to see different hinges operating around them as they provide epistemic counterpoints that enable them 'to detect and sensitize themselves to their blind spots and shared self-ignorance' and 'to feel the contours of [their] social gaze' (Medina 2013: 176, 204).

A second objection was mentioned earlier (footnote 11). Given that the testimonial hinge is apparently universal, while prejudices are apparently local, the hinge account fails to explain how a local hinge can override a universal one with a clearly wider scope. A first response to this objection might actually be that the testimonial hinge can be considered local, too, as it applies to 'people like T', and who 'people like T' are is determined locally; thus, although there is always a default testimonial hinge, its application is nevertheless circumscribed to the specific social group in question, and if it is circumscribed, it is as local as the prejudice. However, the objection voices what I think is a right intuition, namely, that there is an important difference between the testimonial hinge and prejudice; even if both can be considered local, the former seems to be the legitimate linchpin of ordinary testimonial exchanges, while the latter appears as an illicit usurper. To better grasp this difference and reply to the objection, I would like to expand upon another distinction suggested by Coliva and Palmira (2020) that seems appropriate in the case at hand: the distinction between de jure and de facto hinges. De jure hinges are those that cannot be challenged 'without thereby renouncing an entire area of discourse and basic methods of inquiry' (Coliva and Palmira 2020: endnote iv); an example is 'There is an external world'. De facto hinges, conversely, are those presuppositions that are unchallenged in a given society and/or at a given time but that could be challenged, given, for instance, new technological and scientific findings; an example is the hinge 'Nobody has ever been on the moon' (OC 106, 108). ${ }^{16}$ I contend that this distinction does not overlap with the distinction between local and universal hinges; in fact, there can be universal de facto hinges and local de jure hinges. For instance, 'Nobody has ever been on the moon' is (was) a universal and de facto hinge because although it was presumably taken for granted by everyone in the human form of life before a certain time, it was later abandoned as a hinge. In contrast, the dispute between someone who relies on physics and someone who relies on oracles (because of the Weltbild they are embedded in) is a conflict between two hinges that are both local and de jure (OC 609). We might express those hinges as 'Physics predicts the future' and 'The oracle predicts the future': neither of them can be given up without the entire domain of discourse having to do with future expectations being disrupted. (Claiming that the oracle believer is wrong and we physics believers are right is indeed just a restatement of our hinge). ${ }^{17}$ De jure hinges, in other words, are constitutive of the rules of the game we are playing. In contrast, de facto hinges, despite playing an as-a-matter-of-fact hinge role, are ultimately and in the long run not as exempt from reappraisal as de jure hinges.

To apply these distinctions to the case of testimony: both the testimonial hinge and the hinge-prejudice can be considered local, but while prejudices are de facto local hinges, the testimonial hinge is a de jure hinge in that it cannot be challenged without renouncing the entire area of discourse that relates to testimony.

\footnotetext{
${ }^{16}$ Sometimes phrased as 'Nobody can go to the moon' (OC 171, 286).

${ }^{17}$ The worry of relativism might arise here; however, this is not a necessary outcome in the hinge perspective. See Pritchard (2011), Kusch (2016), Coliva (2019b), and Piedrahita (2021).
} 
Therefore, the following questions remain to be clarified: how is it possible that a de facto hinge substitutes a de jure hinge? Is it truly possible given that the de jure hinge cannot be given up without the entire game be given up? My reply is that it is possible; it does indeed happen; and when it happens, the case is often labeled pathological. Take one of our most basic hinges, namely, that there is an external world. One might doubt that there is an external world; their own world and reasoning would be almost irremediably disrupted and substituted with delusional beliefs; they would be, indeed, unreasonable; however, such disruption is, in fact, possible, and it is not a coincidence that the framework of hinge epistemology has been called for in the study of delusions and schizophrenia (Gipps and Rhodes 2008; Bardina 2018; Boncompagni 2018). Similarly, prejudices, i.e., de facto hinges, disrupt and substitute testimonial trust, i.e., a de jure hinge, by preventing evidence from being considered evidence and belief from being considered justified. The result is indeed a pathology of testimonial justification. $^{18}$

Finally, a third objection might be raised concerning the vagueness of the boundary between the hinge 'People like $\mathrm{T}$ are trustworthy' and the prejudice 'People like $\mathrm{T}$ are not trustworthy' (and, relatedly, between de jure and de facto hinges). As a premise for my reply, let me first point out that the precise propositional formulation of hinges is not what is at stake here: although they can be put in propositional form, hinges are essentially implicit presuppositions that show in the way we normally and unreflectively act and judge. The specific way in which we might make them explicit in the shape of full-fledged propositions is secondary. That said, I have no difficulties in admitting the vagueness of the distinction between the testimonial hinge and prejudices and between de jure and de facto hinges; indeed, I would consider this a strength rather than a weakness of my account. It is a strength and not a weakness because such vagueness is part of the reality I am describing, and a good philosophical clarification of the phenomenon should capture such vagueness rather than explaining it away. What counts as 'people

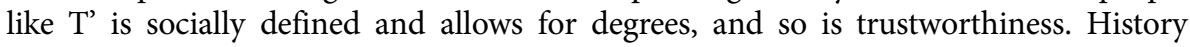
shows that many taken-for-granted presuppositions that at a given time are part of and shape an entire form of life later turn out to be prejudices. The racist hingeprejudice 'Nonwhites are inferior to whites', which shaped - and still partly shapes not only personal convictions but also whole economic and social systems is just one example. The racism that we are now able to detect in Voltaire or Kant is indeed disturbing, not only because it tarnishes their thought but also and foremost because it shakes our own confidence in what we take to be normal, obvious, and uncontroversial. If Kant and Voltaire (and innumerable others) were unable to see their prejudices, how can we hope to see and overcome ours? Many of the certainties that characterize our life today might turn out to be prejudices in the future. Just one more example, that animals can be eaten or used to produce leather and other products, is for most people today obvious and uncontroversial, but it might be considered an abomination in the future. The difficulty in determining the epistemic blameworthiness of prejudices and in distinguishing prejudices from other hinges, in this light, is not a theoretical defect but a theoretical result of the hinge account. A blurred distinction is a distinction, and sometimes, it is the most correct distinction we can draw.

This line of reasoning leads us back to the premises of the paper, and more specifically to the negative characterization of prejudices that I decided not to dispute. While I

\footnotetext{
${ }^{18}$ Another way to address the second objection to which I can only hint is by arguing along the lines of Pritchard $(2016,2018)$ that one general über-hinge regulates testimonial justification, but such über-hinge can be codified and actualized in different ways. In this framework, prejudice becomes a wrong codification of the über-hinge.
} 
do think that prejudices as disparaging generalizations that target marginalized groups are rightly characterized in negative terms, I also think that there is not a sharp boundary between prejudices and innocuous commonsense hinges, that this should keep us alert, and that more research on this middle territory is desirable. Hinge epistemology offers a good framework for such investigations.

\section{Conclusion}

I claimed that research concerning epistemic injustice focuses on the effects of prejudice in our epistemic practices but is still wanting with respect to the very notion of prejudice that it employs, particularly with respect to the role of prejudice in testimonial justification. Building on hinge epistemology, I have proposed a hinge account of prejudice in which a key feature of prejudice -its normative role - comes to the fore. Because, like hinges, they work as norms of evidential significance, prejudices determine what can and what cannot count as evidence; in the case of testimony, their normative power results from the preemption of the evidential significance of the speaker's words for the hearer's belief. This account also clarifies other aspects involved in the notion of prejudice, namely, resistance to counterevidence (counterevidence is not taken as evidence at all when a prejudice is in place) and the different steps involved in the overcoming of prejudice (a prejudice, in order to be seen as a prejudice, must not only emerge but also lose its normative power). Considering some possible objections to the hinge account, I have argued that prejudices should be considered local de facto hinges, a characterization that invites further research on the blurred boundaries between prejudices and commonsense taken-for-granted presuppositions. ${ }^{19}$

\section{References}

Alcoff L. (2010). 'Epistemic Identities.' Episteme 7, 128-37.

Ashton N. (2019). 'The Case for a Feminist Hinge Epistemology.' Wittgenstein Studien 10, 153-63.

Bardina S. (2018). 'Abnormal Certainty: Examining the Epistemological Status of Delusional Beliefs.' International Journal of Philosophical Studies 26(4), 546-60.

Begby E. (2013). 'The Epistemology of Prejudice.' Thought 2(2), 90-9.

Begby E. (2020). 'Evidential Preemption.' Philosophy and Phenomenological Research. doi: 10.1111/ phpr.12654.

Boncompagni A. (2014). 'On Trying to Say What 'Goes without Saying': Wittgenstein on Certainty and Ineffability.' Ricerche di Pedagogia e Didattica - Journal of Theories and Research in Education 9(1), 51-68.

Boncompagni A. (2018). 'Common Sense, Philosophy, and Mental Disturbance: A Wittgensteinian Outlook.' In J. Gonçalves, I.V. Hipólito and J. Pereira (eds), Schizophrenia and Common Sense. Explaining the Relation between Madness and Social Values, pp. 227-38. London: Springer Nature.

Boncompagni A. (2019). 'Hinges, Prejudices and Radical Doubters.' Wittgenstein-Studien 10, 165-81.

Cassam Q. (2016). 'Vice Epistemology.' The Monist 99, 159-80.

Castelli L. and Tomelleri S. (2008). 'Contextual Effects on Prejudiced Attitudes: When the Presence of Others Leads to More Egalitarian Responses.' Journal of Experimental Social Psychology 44(3), 679-86.

Christensen D. (2010). 'Higher-Order Evidence.' Philosophy and Phenomenological Research 81, $185-215$.

\footnotetext{
${ }^{19}$ Previous versions of this work were presented at a Brown Bag seminar at UC Irvine (2019), the UC President Postdoctoral Fellowship Program Retreat (2019) and a graduate seminar that I co-taught at UC Irvine (2020). I would like to thank the audiences for their precious feedback, and in particular Annalisa Coliva for extensive and valuable exchanges throughout this couple of years, Sven Bernecker for helpful feedback and suggestions, and UCI graduate students Giulia Napolitano, Oscar Piedrahita and Tanuj Raut for very productive conversations. Many thanks also to an anonymous reviewer and the editors at Episteme for their comments.
} 
Code L. (2008). 'Advocacy, Negotiation, and the Politics of Unknowing.' Southern Journal of Philosophy XLVI, 32-51.

Coliva A. (2015). Extended Rationality: A Hinge Epistemology. Basingstoke: Palgrave Macmillan.

Coliva A. (2019a). 'Testimonial Hinges.' Philosophical Issues 29, 53-68.

Coliva A. (2019b). 'Relativism and Hinge Epistemology.' In M. Kusch (ed.), The Routledge Handbook of the Philosophy of Relativism, pp. 320-8. London: Routledge.

Coliva A. (Forthcoming). 'Social Hinge Epistemology.' In J. Lackey and A. McGlynn (eds), The Oxford Handbook of Social Epistemology. Oxford: Oxford University Press.

Coliva A. and Moyal-Sharrock D. (eds) (2016). International Journal for the Study of Skepticism 6(2-3), Double Special Issue: 'Hinge Epistemology'.

Coliva A. and Palmira M. (2020). 'Hinge Disagreement.' In N.A. Ashton, M. Kusch, R. McKenna and K.A. Sodoma (eds), Social Epistemology and Relativism, pp. 11-29. New York, NY: Routledge.

Coliva A. and Palmira M. (Forthcoming). 'Disagreement Unhinged.' Metaphilosophy.

Collingwood R.G. (1940). An Essay on Metaphysics. Oxford: Oxford University Press.

Collins P.H. (2000). Black Feminist Thought: Knowledge, Consciousness, and the Politics of Empowerment. New York, NY: Routledge.

Constantine J. and Grundmann T. (2018). 'Epistemic Authority: Preemption Through Source Sensitive Defeat.' Synthese. doi: 10.1007/s11229-018-01923-x.

Dormandy K. (2018). 'Epistemic Authority: Preemption or Proper Basis?' Erkenntnis 83, 773-91.

D’Oro G. (2018). 'Why Epistemic Pluralism Does not Entail Relativism: Collingwood's Hinge Epistemology.' In K. Dharamsi, G. D'Oro and S. Leach (eds), Collingwood on Philosophical Methodology, pp. 151-75. Cham: Palgrave Macmillan.

Feldman R. (2005). 'Respecting the Evidence.' Philosophical Perspectives 19, 95-119.

Fogelin R. (2005 [1985]). 'The Logic of Deep Disagreements.' Informal Logic 25, 3-11. [1985, Informal Logic 7, 1-8.]

Fricker M. (2007). Epistemic Injustice: Power and the Ethics of Knowing. Oxford: Oxford University Press.

Gadamer H.-G. (1975). Truth and Method. New York, NY: The Seabury Press.

Gadamer H.-G. (1976). Philosophical Hermeneutics. Berkeley, CA: University of California Press.

Gipps R.G.T. and Rhodes J. (2008). 'Delusions, Certainty, and the Background.' Philosophy, Psychiatry, and Psychology 15(4), 295-310.

Greco J. (2016). 'Common Knowledge.' International Journal for the Study of Skepticism 6, 309-25.

hooks b. (1992). Black Looks: Race and Representation. Brooklyn, NY: South End Press.

Jäger C. (2016). 'Epistemic Authority, Preemptive Reasons, and Understanding.' Episteme 13(2), 167-85.

Kappel K. (2018). 'Higher Order Evidence and Deep Disagreement.' Topoi. doi: https://doi.org/10.1007/ s11245-018-9587-8.

Keren A. (2007). 'Epistemic Authority, Testimony, and the Transmission of Knowledge.' Episteme 4(3), $368-81$.

Keren A. (2014a). 'Zagzebski on Authority and Preemption in the Domain of Belief.' European Journal for Philosophy of Religion 6, 61-76.

Keren A. (2014b). 'Trust and Belief: A Preemptive Reason Account.' Synthese 191(12), 2593-616.

Kusch M. (2016). 'Wittgenstein's On Certainty and Relativism.' In S. Rinofner-Kreidl (ed.), Analytic and Continental Philosophy. Methods and Perspectives. Proceedings of the 37th International Wittgenstein Symposium, pp. 29-46. Berlin: De Gruyter.

Lackey J. (2011). 'Testimony. Acquiring Knowledge from Others.' In A.I. Goldman and D. Whitcomb (eds), Social Epistemology: Essential Readings, pp. 71-91. Oxford: Oxford University Press.

Lagewaard T.J. (2020). 'Epistemic Injustice and Deepened Disagreement.' Philosophical Studies. doi: 10.1007/s11098-020-01496-x.

McKinnon R. (2016). 'Epistemic Injustice.' Philosophy Compass 11(8), 437-46.

Medina J. (2013). The Epistemology of Resistance. Oxford: Oxford University Press.

Moore G.E. (1925). 'A Defense of Common Sense.' Reprinted in Philosophical Papers. London: George Allen \& Unwin.

Moore G.E. (1939). 'Proof of an External World.' Reprinted in Philosophical Papers. London: George Allen \& Unwin.

Moraga C. and Anzaldúa G. (eds) (1981). This Bridge Called My Back: Writings by Radical Women of Color. London: Persephone Press.

Moyal-Sharrock D. (2004). Understanding Wittgenstein's On Certainty. London: Palgrave Macmillan. 
Newman J.H. (1979). An Essay in Aid of a Grammar of Assent. Notre Dame, IN: University of Notre Dame Press.

O'Hara N. (2018). Moral Certainty and the Foundations of Morality. Cham: Palgrave Macmillan.

Peirce C.S. (1935 [1905a]). 'Six Characters of Critical Common-Sensism.' In The Collected Papers of Charles Sanders Peirce, Vol. 5. Cambridge, MA: Harvard University Press.

Peirce C.S. (1935 [1905b]). 'Consequences of Critical Common-Sensism.' In The Collected Papers of Charles Sanders Peirce, vol. 5. Cambridge, MA: Harvard University Press.

Piedrahita O. (2021). 'Can Hinge Epistemology Close the Door on Epistemic Relativism?' Synthese. doi: https://doi.org/10.1007/s11229-020-02995-4.

Pritchard D. (2011). 'Epistemic Relativism, Epistemic Incommensurability, and Wittgensteinian Epistemology.' In S. Hales (ed.), A Companion to Relativism, pp. 266-85. Oxford: Wiley Blackwell.

Pritchard D. (2016). Epistemic Angst: Radical Skepticism and the Groundlessness of our Believing. Princeton, NJ: Princeton University Press.

Pritchard D. (2018). 'Wittgensteinian Hinge Epistemology and Deep Disagreement.' Topoi. doi: https://doi. org/10.1007/s11245-018-9612-y.

Ranalli C. (2018). 'Deep Disagreement and Hinge Epistemology'. Synthese. doi: https://doi.org/10.1007/ s11229-018-01956-2.

Reid T. (1997 [1764]). An Inquiry Into the Human Mind on the Principles of Common Sense. University Park, PA: Pennsylvania State University.

Reid T. (2002 [1785]). Essays on the Intellectual Powers of Man. University Park, PA: Pennsylvania State University Press.

Schönbaumsfeld G. (2016). The Illusion of Doubt. Oxford: Oxford University Press.

Silva P. (2020). 'A Bayesian Explanation of the Irrationality of Sexist and Racist Beliefs Involving Generic Content.' Synthese 197, 2465-87.

Spivak G.C. (2003). 'Can the Subaltern Speak?' Die Philosophin 14(27), 42-58.

Wittenbrink B., Judd C.M. and Park B. (2001). 'Spontaneous Prejudice in Context: Variability in Automatically Activated Attitudes.' Journal of Personality and Social Psychology 81(5), 815-27.

Wittgenstein L. (1969). On Certainty. Oxford: Blackwell.

Wittgenstein L. (2009). Philosophical Investigations. Oxford: Wiley-Blackwell.

Wright S. (2016). 'Epistemic Authority, Epistemic Preemption, and the Intellectual Virtues.' Episteme 13 (4), 550-70.

Zagzebski L.T. (1996). Virtues of the Mind: An Inquiry into the Nature of Virtue and the Ethical Foundations of Knowledge. Cambridge: Cambridge University Press.

Zagzebski L.T. (2012). Epistemic Authority: A Theory of Trust, Authority and Autonomy in Belief. Oxford: Oxford University Press.

Anna Boncompagni is Assistant Professor at the Department of Philosophy of the University of California, Irvine. She has been working extensively on Wittgenstein's philosophy and is also interested in pragmatism, feminist epistemology, and the history of analytic philosophy. Her current research focuses on a Wittgensteinian understanding of pressing issues in social epistemology, such as the nature of common sense and of prejudice. Her publications include the monograph Wittgenstein and Pragmatism: On Certainty in the Light of Peirce and James (2016).

Cite this article: Boncompagni A (2021). Prejudice in Testimonial Justification: A Hinge Account. Episteme 1-18. https://doi.org/10.1017/epi.2021.40 